\title{
Usos medicinais de plantas no Cariri paraibano: um estudo de caso
}

\author{
Medicinal uses of plants in the Cariri from paraibano: a case study
}

Usos medicinales de las plantas en el cariri paraibano: un estudio de caso

\author{
Débora Coelho Moura ${ }^{1}$ \\ Marcela de Souza Silva Alves ${ }^{2}$ \\ Erimágna de Morais Rodrigues ${ }^{3}$ \\ Antonio James Oliveira Silva ${ }^{4}$ \\ Aureliana Santos Gomes ${ }^{5}$
}

\begin{abstract}
Resumo
MOURA, D. C.; ALVES, M. de S. S.; RODRIGUES, E. de M.; SILVA, A. J. O.; GOMES, A. S. Usos medicinais de plantas no Cariri paraibano: um estudo de caso. Rev. CઐTrópico, v. 44, n.1, p. 217 233, 2020. DOI: https://doi.org/10.33148/cetropicov44n1(2020)art10
\end{abstract}

Esse trabalho é pioneiro no estudo de uso de plantas medicinais, no município de Gado Bravo-PB. Assim, este estudo apresenta-se com finalidade de levantar o histórico etnobotânico das plantas medicinais, que é comum em diversas comunidades humanas. No município de Gado Bravo-PB, o uso de plantas medicinais é comum entre seus respectivos moradores, pois eles utilizam-nas como terapia, alívio de dores e doenças consideradas simples. O objetivo deste estudo foi resgatar e sistematizar as informações populares sobre as plantas medicinais utilizadas na cidade. Foi realizado um estudo em três ruas, com 40 pessoas, de sexo e faixa etária diferentes. Foram citadas neste estudo 16 famílias botânicas de 26 espécies de plantas medicinais usadas como terapia pela comunidade. Apenas duas plantas entre as 16 citadas pertencem ao bioma Caatinga, que é a Aroeira (Myracrodruon urundeuva M. Allemão), e a Malva Rosa (Melochia tomentosa L.). As demais são exóticas. Durante as entrevistas, os moradores demostraram, que a população possui um grande conhecimento acerca das plantas medicinais e suas propriedades terapêuticas.

Palavras-chave: Gado Bravo-PB. Caatinga. Plantas Medicinais.

\footnotetext{
Prof. Associada da Universidade Federal de Campina Grande. Doutora em Biologia Vegetal pela Universidade Federal de Pernambuco-UFPE. E-mail: debygeo@hotmail.com. ORCID: https://orcid.org/0000-0003-2663-2308

2 Mestranda em Educação pela UNINOVE. E-mail: marcelasouzageoufcg@gmail.com.ORCID: https://orcid. org/0000-0003-2192-6163

3 Doutoranda em Ecologia pela Universidade Federal do Rio de Janeiro. E-mail: erimagnarodrigues@gmail.com. ORCID: https://orcid.org/0000-0003-4281-3555

4 Mestrando em Informática e gestão do conhecimento- UNINOVE. E-mail: tecgeo.oliveirajames@gmail.com. ORCID: https://orcid.org/0000-0002-0722-7123

5 Graduanda do curso de Geografia da Universidade Federal de Campina Grande- UFCG. aurelianagomes7@ gmail.com
} 


\section{Abstract \\ MOURA, D. C.; ALVES, M. de S. S.; RODRIGUES, E. de M.; SILVA, A. J. O.; GOMES, A. S. Medici- nal uses of plants in the Cariri from paraibano: a case study. Rev. C\&Trópico, v. 44, n.1, p. 217-233, 2020. DOI: https://doi.org/10.33148/cetropicov44n1(2020)art10}

This work is a pioneer in the study of the use of medicinal plants, in the municipality of Gado Bravo/Paraiba. Thus, this study aims to present the historical and ethnobotanical rescue of medicinal plants, which is common in several human communities. In the municipality of Gado Bravo, the use of medicinal plants is common among their respective residents, as they use them as therapy, pain relief and diseases considered simple. The objective of this study was to rescue and systematize popular information about medicinal plants used in the city. A study was carried out in three streets, with 40 people, of different gender and age, respectively. In this study, 16 botanical families of 26 species of medicinal plants used were cited as therapy by the community. Only two plants among the 16 mentioned belong to the Caatinga biome, which are Aroeira (Myracrodruon urundeuva Allemão), and Malva Rosa (Melochia tomentosa L.). the others are exotic. During the interviews, residents demonstrated that the population has a great deal of knowledge about medicinal plants and their therapeutic properties.

Keywords: Gado Bravo-Paraíba. Caatinga. Medicinal Plants.

\section{Resumen}

MOURA, D. C.; ALVES, M. de S. S.; RODRIGUES, E. de M.; SILVA, A. J. O.; GOMES, A. S. Usos medicinales de las plantas en el cariri paraibano: un estudio de caso. Rev. CひTrópico, v. 44, n.1, p. 217-233, 2020. DOI: https://doi.org/10.33148/cetropicov44n1(2020)art10

Este trabajo es pionero en el estudio del uso de plantas medicinales, en el municipio de Gado Bravo-Paraíba. Por lo tanto, este estudio se presenta con el propósito de rescatar histórica y etnobotánica de plantas medicinales, lo cual es común en varias comunidades humanas. En el municipio de Gado Bravo-PB, el uso de plantas medicinales es común entre sus respectivos residentes, ya que las utilizan como terapia, alivio del dolor y enfermedades consideradas simples. El objetivo de este estudio fue rescatar y sistematizar la información popular sobre las plantas medicinales utilizadas en la ciudad. Se realizó un estudio en tres calles, con 40 personas, de diferente sexo y edad, respectivamente. En este estudio, la comunidad citó a 16 familias botánicas de 26 especies de plantas medicinales utilizadas como terapia. Solo dos plantas entre las 16 mencionadas pertenecen al bioma Caatinga, que es la Aroeira (Myracrodruon urundeuva M. Allemão) y la Malva Rosa (Melochia tomentosa L.), las otras son exóticas. Durante las entrevistas, los residentes demostraron que la población tiene un gran conocimiento sobre las plantas medicinales y sus propiedades terapéuticas.

Palabras clave: Gado Bravo-Paraíba. Caatinga, Plantas Medicinales

Data de submissão: 01/04/2020

Data de aceite: 30/04/2020 


\section{Introdução}

O uso de plantas com algum fim medicinal possui registro em diferentes épocas da humanidade, sendo utilizadas de forma empírica por vários grupos populacionais, tornando-se uma questão cultural, que permanece até os dias atuais. A transmissão do conhecimento relacionado ao uso de plantas com fins medicinais é repassada de geração para geração de forma oral, se caracterizando como recurso essencial às comunidades (NÓBREGA, et al. 2017).

No Brasil, o estudo das plantas medicinais tem sido evidenciado pelas novas tendências de preocupação, com a biodiversidade, através das ideias de desenvolvimento sustentável, atrelado ao baixo poder aquisitivo da população, que residem em regiões Norte e Nordeste (FLORENTINO et al. 2007; PEREIRA et al, 2016; PIO et al. 2019). Por outro lado, o resgate histórico cultural das comunidades tradicionais sobre as plantas medicinais fez com que a Organização Mundial de Saúde (OMS) propusesse aos órgãos responsáveis pela saúde pública de cada país medidas que viabilizassem diminuir o número de excluídos dos sistemas governamentais de saúde.

Tais medidas propostas foram o levantamento florístico das plantas medicinais a nível regional que fossem usadas na medicina popular tradicional. Que, através desse levantamento florístico, fossem estimuladas e recomendadas as espécies de maior uso e aquelas que tivessem comprovação terapêutica. A partir daí seriam desenvolvidos programas que permitissem cultivar e utilizar as plantas selecionadas na forma de preparações dotadas de eficácia, segurança e qualidade (PERNA; FERREIRA, 2014; ANDRADE, et al. 2017; PIO et al. 2019).

A Região Nordeste, por possuir comunidades tradicionais, possivelmente, com base social de menor valor aquisitivo, torna comum o uso pela população das plantas medicinais. Torna-se notório o número crescente de farmácias alopáticas nos municípios brasileiros, contudo os usos destas plantas são disseminados tanto no meio rural e urbano. Segundo Martins et al, (2005), Oliveira; Mezzomo; Moraes (2018) aliados às informações etnobotânicas, a procura por essas plantas podem ser a relação custo/benefício. Mosca et al, (2009); Cerqueira et al. (2020) comentam que $90 \%$ da população economicamente carente do Nordeste recorre às plantas medicinais para a cura de seus problemas de saúde.

Justifica-se este trabalho como pioneiro no município, tratando-se do uso e diversidade de plantas medicinais. Isso ressalta a necessidade de estudos que corroborem a diversidade florística sobre o uso dos recursos da flora em Gado Bravo. Este estudo teve como objetivo levantar o resgate histórico e etnobotânico das plantas medicinais. Para tanto, buscou inventariar as espécies vegetais e caracterizar o uso dessas através de alguns moradores do município de Gado Bravo-PB. 


\section{Materiais e métodos}

\section{1. Área de estudo}

A pesquisa foi realizada no município de Gado Bravo, localizado na região intermediária de Campina Grande-PB, Nordeste do Brasil (Figura 1). Situado a 470 metros de altitude, Gado Bravo apresenta clima Semiárido, e encontra-se sob as coordenadas geográficas: Latitude: $7^{\circ} 32^{\prime} 35^{\prime \prime}$ Sul, Longitude: $35^{\circ} 48^{\prime} 2^{\prime \prime}$ Oeste (IBGE, 2010). O município possui cerca de 8.376 habitantes e uma densidade demográfica de $43,53 \mathrm{hab} / \mathrm{km}^{2}$.

Figura 1: Mapa de localização do município de Gado Bravo.
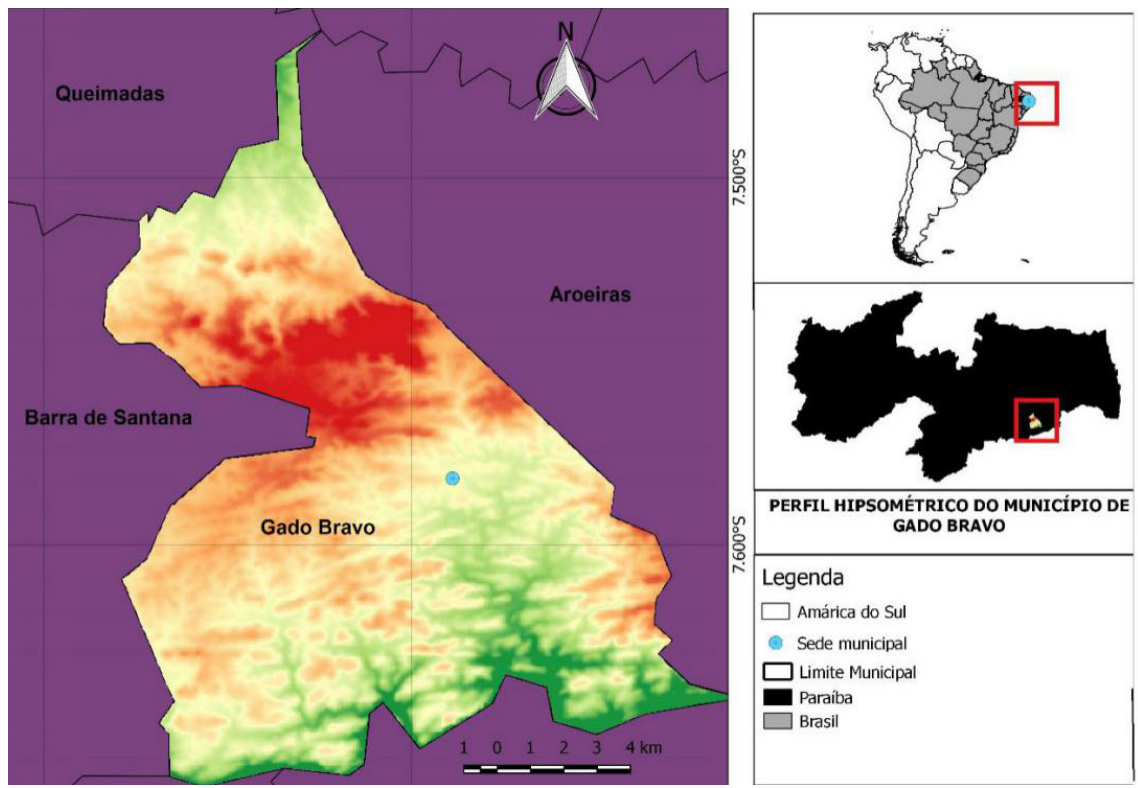

Fonte: RODRIGUES, E.M. 2020.

\subsection{Caracterização sociocultural}

A cidade de Gado Bravo-PB surgiu como uma pequena vila, pertencente à Cidade de Umbuzeiro na época, e tem sua origem ligada a uma casa de farinha no final do século XIX início do século XX. A população provém de migrações principalmente do estado de Pernambuco. Essa cidade apresentava, no passado, como principais atividades econômicas a agropecuária, pesca e caça. A partir da década de 1990, várias transformações aconteceram, entre elas a emancipação política, tornando Gado Bravo um município. Desde então, surgiram pequenos comerciantes, funcionários públicos e o comércio local dos pequenos feirantes, que adentraram o perímetro urbano. 
A diversidade sociocultural da área é proveniente da estrutura fundiária, em que a agricultura de subsistência atrelada à pecuária leiteira corroboraram para o fortalecimento da economia local. As comunidades tradicionais representadas no município foram estabelecidas pelo inter-relacionamento, com seus respectivos ambientes geográficos, como proximidade do rio Paraibinha (Figura 2), e a produção de algodão e sisal, como fonte de renda (RODRIGUES, et al. 2015).

Figura 2: Drenagem circundante o perímetro urbano do município de Gado Bravo.

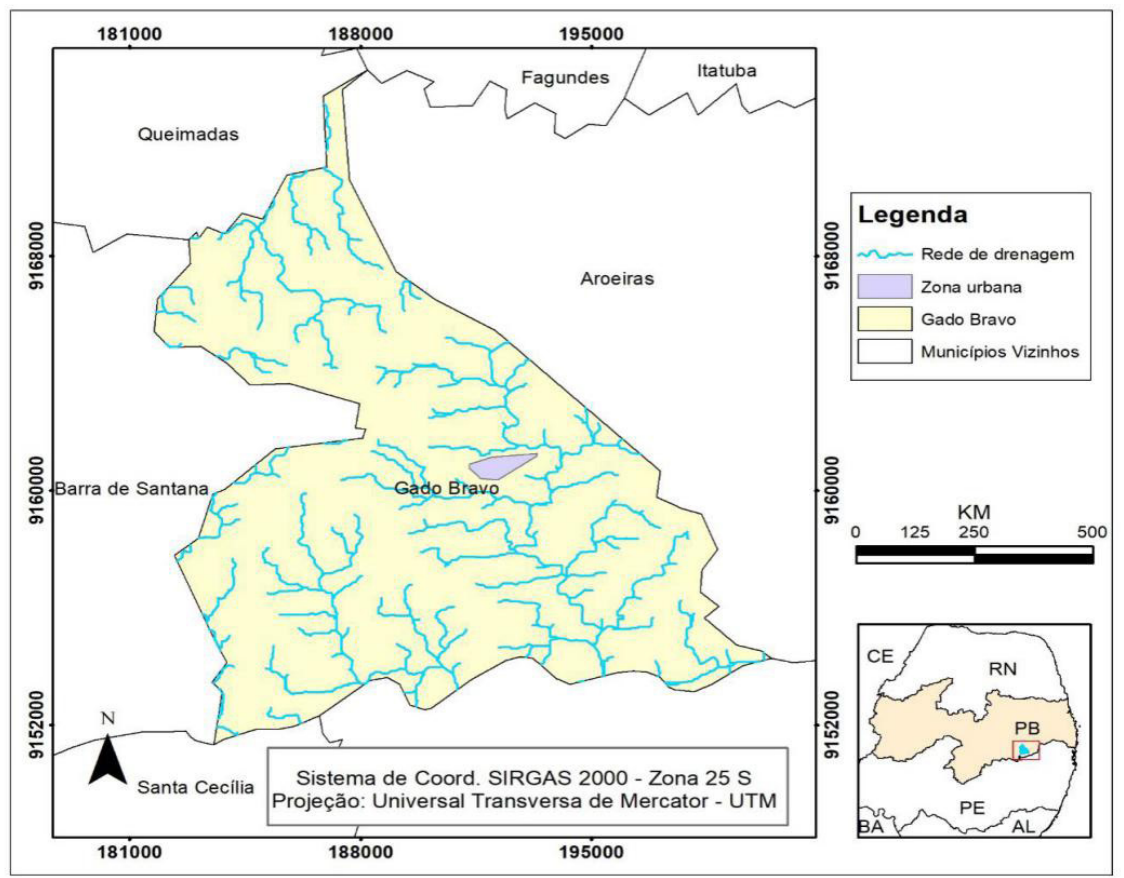

Fonte: Elaborado por SILVA, A.J.O 2020.

O município registrou nos últimos dez anos, até 2019, subsídios sociais de origem federal, que mantém o homem no campo, proporcionando-lhe um suporte alimentar e financeiro, como Bolsa Familia ${ }^{1}$ e Seguro Safra ${ }^{2}$, que atenuam as necessidades básicas.

Diante de uma população pobre e carente, é notória a importância do uso de plantas medicinais, visto que as condições socioeconômicas dos moradores são precárias e as plantas podem ser nesse sentido, um método de cura eficaz, com valor bastante inferior ao dos medicamentos alopáticos. Portanto, torna-se necessário ser repassado o conhecimento popular, sobre o uso de plantas medicinais para as próximas gerações, no intuito de disseminar esse saber, que é importante para todos. 


\subsection{Coleta de dados}

Os dados etnobotânicos foram registrados em três ruas do município de Gado Bravo. As ruas foram: José Pereira de Aguiar, Severino Felipe Barbosa e José Henrique da Silva (Figura 3). A pesquisa foi realizada em um período de dois meses, agosto e setembro de 2018. Foram aplicados 40 questionários semiestruturados, segundo metodologia utilizada por Albuquerque; Lucena, (2004), buscando obter informações sobre o potencial medicinal e características botânicas das plantas utilizadas. O questionário padronizado foi utilizado para identificar as espécies vegetais: o nome da planta, enfermidade combatida, origem da planta, parte utilizada e posologia: forma de utilização, quantidade (quantas vezes ao dia e tempo de uso).

Figura 3: Localização das áreas amostrais em que foram realizadas as entrevistas na cidade de Gado Bravo.



Fonte: Elaborado por RODRIGUES, E.M.2020.

Foram entrevistados 40 (quarenta) moradores entre 21 e 80 anos, sendo considerados especialistas locais (raizeiros, mateiros, agricultores, rezadeiras, donas de casa). Utilizou-se como técnica de amostragem a metodologia proposta por Bailey (1994), chamada "bola de neve" (snow ball), em que o primeiro especialista entrevistado indica o próximo, e assim por diante, até chegar ao final do estudo, quando todos os especialistas da comunidade foram entrevistados. Para o levantamento dos dados, foram empregados os métodos de coleta de informações quantitativas, que se classifica 
como descritiva, a qual tem como propósito realizar a descrição das particularidades de alguma população ou fenômeno, ou a determinação de relações entre variáveis. Uma das peculiaridades importantes deste tipo de pesquisa é a aplicação de métodos padronizados de coleta de informações, como por exemplo, a entrevista, o formulário, o questionário, o teste e a observação (NOBREGA, et al. 2017; FIEBIG, PASA, 2018).

A frequência relativa das plantas medicinais foi calculada no Programa Excel, conforme Martins (1979), Castro (1987), Fiebig; Pasa, (2018). Apenas as plantas que apresentaram frequência de citação $\geq 5 \%$ foram consideradas para fins de discussão. Um check list foi elaborado contendo nomes científicos e populares, bem como finalidades terapêuticas, formas de uso, parte(s) utilizada(s) e indicação das espécies mencionadas pelos informantes locais. As identificações das espécies ocorreram na atividade de campo (visitas). O nome científico foi consultado nas plataformas online do Jabot ${ }^{6}$, bem como na Flora do Brasil 2020 (reflora) ${ }^{7}$. Nesta pesquisa, foram registradas as espécies medicinais nativas e exóticas, sendo consideradas, para fins de discussão, as espécies com frequência de citação $\geq 5 \%$, por terem sido citada diversas vezes entre os entrevistados. Para comprovar o nome das espécies, utilizou-se bibliografia especializada.

\section{Resultados e discussões}

\section{1. levantamento sociocultural}

O estudo foi realizado em 40 residências na cidade de Gado Bravo, Paraíba, com faixa etária dos entrevistados entre 21 e 80 anos, sendo 97,5\% do gênero feminino, pois os homens estavam a trabalhar na agricultura, enquanto as mulheres permanecem fazendo as atividades do lar. Segundo o IBGE (2010, estimada em 2019), a população da cidade de Gado Bravo-PB possui um rendimento em média de 1,7 salário mínimo mensal. A proporção de pessoas ocupadas em relação à população total era, com base no censo de 2010, estimada em 2019 de 6\%, como funcionário público municipal, como a maioria da população, residente em municípios interioranos.

Analisando o ranking populacional com ocupação remunerada, Gado Bravo ocupa a quinquagésima quinta posição do total de 223 municípios. Considerando os domicílios com rendimentos mensais de até meio salário mínimo por pessoa, o território municipal registrava $57,3 \%$ da população, em que o Índice de Desenvolvimento Humano Municipal (2010 estimado em 2019) de 0,513 é considerado abaixo da linha de pobreza.

Com base nos questionários, foi constatado que a população do município possui uma renda de até um salário mínimo, e cerca de $60 \%$ não concluiu o Ensino Fundamental I, evidenciando-se uma população com pouco conhecimento escolar (Tabela 1). Em trabalhos realizados por Almeida (2019), Pio et al. (2019) e Cerqueira

\footnotetext{
Disponível em: http://rb.jbrj.gov.br/v2/consulta.php

Disponível em: http://floradobrasil.jbrj.gov.br.
} 
et al. (2020), os resultados apontam que os principais atores, que manipulam as plantas medicinais (raizeiros), não possuem instrução superior, e, no máximo, concluíram o primeiro ciclo do Ensino Fundamental (antiga $4^{\text {a }}$ série). Além disso, a ausência da perpetuação da profissão para os descendentes caiu em virtude do afastamento precoce dos filhos do seio familiar, devido à falta de interesse e inserção no ambiente escolar. Contudo, o conhecimento popular sobre as plantas medicinais, se sobressaem ao ensino escolar. Os entrevistados que não são aposentados são agricultores e donas de casa.

Tabela 1. Informações socioculturais dos entrevistados em Gado Bravo.

\begin{tabular}{c|c|c}
\hline \multirow{2}{*}{ Informações mais relevantes } & Entrevistados $(\mathbf{n}=\mathbf{4 0})$ & $\mathbf{\%}$ \\
\hline \multirow{4}{*}{ Faixa etária } & $21-35$ anos & $35 \%$ \\
\cline { 2 - 3 } & $36-50$ anos & $22,5 \%$ \\
\cline { 2 - 3 } & $51-60$ anos & $20 \%$ \\
\cline { 2 - 3 } Representatividade de gênero & $61-80$ anos & $95 \%$ \\
\cline { 2 - 3 } & Feminino & $5 \%$ \\
\hline \multirow{2}{*}{ Representatividade de moradores } & Masculino & $97,5 \%$ \\
\cline { 2 - 3 } & Oriundos & $2,5 \%$ \\
\hline \multirow{2}{*}{ Renda familiar } & Não oriundos & $82,5 \%$ \\
\cline { 2 - 3 } & Até 1 salário mínimo & $17,5 \%$ \\
\hline \multirow{3}{*}{ Grau de escolaridade } & 1 a 2 salários mínimos & $60 \%$ \\
\cline { 2 - 3 } & Analfabeto & $12,5 \%$ \\
\cline { 2 - 3 } & $1^{\circ}$ grau incompleto & $5 \%$ \\
\cline { 2 - 3 } & $1^{\circ}$ grau completo & $5 \%$ \\
\cline { 2 - 3 } & $2^{\circ}$ incompleto & $2,5 \%$ \\
\cline { 2 - 3 } & $2^{\circ}$ completo & $0 \%$ \\
\hline
\end{tabular}

Fonte: Elaborado pelos autores.

O povoado, que surgiu no final do século XIX, era denominado Curtume, hoje conhecido como município de Gado Bravo. Os primeiros moradores deste lugarejo, citados pelos entrevistados, eram pessoas ilustres, como as parteiras e rezadores; conhecedores da manipulação das plantas, bem como posologia, além de fazerem associação com orações que "traziam a cura". Na década de 1970, a atividade de parteira era comum em pequenos povoados. O município homenageia a "Senhora Felipa", que se tornou a madrinha de várias crianças, pois ela se deslocava de sua residência para atender as parturientes. Os serviços eram sempre voluntários.

No município, existia também um rezador, conhecido como "Sr. Zé Ciço", o qual rezava contra o "mal-olhado" e "peito aberto". Ele tinha sua residência bastante movimentada, pois rezava em crianças e adultos. Essas informações da história da cidade foram cedidas pela Prefeitura municipal de Gado Bravo. Na zona urbana, não foram encontrados rezadores, contudo na área rural são encontrados, além de rezadores, os garrafeiros. Esses moradores coletam as plantas medicinais direto do campo, ou seja, da vegetação de Caatinga, e após o parto indicavam-se garrafadas para as 
mulheres, uma mistura de plantas medicinais (mastruz, arruda, alfazema), com cachaça, cebola branca e açúcar.

O município possui um Posto de Saúde “Abdias Albuquerque de Farias”, uma Policlínica e a Unidade de Saúde "Madrinha Felipa", que atende as necessidades médicas da população. De acordo com informações obtidas no posto de saúde, não há programas relacionados ao uso de plantas medicinais, normalmente os médicos prescrevem remédios alopáticos, para os usuários dos serviços de saúde.

\subsection{Levantamento etnobotânico}

A flora medicinal citada pelos moradores de Gado Bravo é amplamente conhecida por seus moradores. Entretanto são também usados medicamentos fitoterápicos e a base de plantas medicinais, tais como: pomadas, xaropes, soluções tópicas cicatrizantes, garrafadas entre outros.

Ao analisar as notificações das plantas medicinais mencionadas pelos entrevistados, cerca de $73 \%(\mathrm{n}=28)$ teriam adquirido esses conhecimentos, com os pais ou parentes próximos. Essa forma de transferência sobre o uso tradicional dos recursos vegetais prevalece em diferentes culturas (SILVA et al. 2015; FREITAS; FERNANDES, 2017), nos mais diversos biomas. Trabalhos realizados no Cerrado, Amazônia e Caatinga evidenciam o declínio de muitas informações e práticas sobre os usos das plantas, principalmente das medicinais, devido à influência da mídia televisiva, que influencia a medicação alopática. Essa perda de conhecimento poderá acarretar em jovens e adultos sem informação de sua origem, e gradativamente perda das heranças culturais (OLIVEIRA et al, 2010; MACEDO et al, 2015, MARTELLI; CARVALHO,2019).

Em Gado Bravo, como nos demais locais, as mulheres demonstram forte interesse sobre as plantas medicinais, todavia elas disponibilizam maior tempo em casa e se responsabilizam pelos cuidados com a saúde de filhos e netos (PEREIRA et al. 2016). Por meio de relatos dos entrevistados, foi possível verificar que utilizam as ervas medicinais por acreditarem em sua eficácia e na cura através das plantas, porquanto são mais naturais, apresentando mais benefícios à saúde do que o medicamento sintético (relato de campo).

Neste estudo, foram levantadas 16 famílias botânicas de 26 espécies de plantas medicinais, usadas como terapia pela comunidade. As plantas citadas pelos entrevistados são encontradas nos quintais dos moradores e em supermercados. Assim, Albertasse et al. (2010); Cerqueira et al. (2020) discutem que, a partir da predição simples relacionada ao uso em abundância em que as plantas são encontradas, facilmente podem oferecer maiores possibilidades de uso. Porquanto, a população local pode experimentar e aprender o uso, permitindo a perpetuação do conhecimento e utilização.

A Tabela 2 apresenta as plantas citadas pelos moradores, evidenciando também as mais utilizadas e compradas pela população. Cada entrevistado citava as plantas mais utilizadas e indicava para qual enfermidade serviam, além de fazer referência 
à origem ou localidade que adquiriu a espécie, (município, estado). Apesar de o estudo ter sido realizado em área de vegetação Caatinga, apenas duas plantas fazem parte desse bioma: a Aroeira (Myracrodruon urundeuva M. Allemão), e a Malva Rosa (Melochia tomentosa L.). As demais são exóticas.

O modo de uso das plantas mais citados foram a infusão e a decocção, seguido de maceração, sucos e banhos (Tabela 3). As partes das plantas que os entrevistados utilizam com maior frequência são as folhas, flores, frutos, enquanto as sementes e rizoma têm menor uso. Várias doenças foram citadas pelos moradores, sendo elas simples, de baixo risco, sobre as quais as plantas são eficazes para o tratamento e cura.

Tabela 3: Listagem da flora medicinal citadas pelos entrevistados em Gado Bravo, relacionada às famílias, nomes vernaculares, indicação terapêutica, parte utilizada, modo de uso e origem.

\begin{tabular}{|c|c|c|c|c|c|}
\hline Família/especie & $\begin{array}{c}\text { Nome } \\
\text { vernacular }\end{array}$ & $\begin{array}{l}\text { Indicação } \\
\text { terapêutica }\end{array}$ & $\begin{array}{c}\text { Parte } \\
\text { utilizada }\end{array}$ & Modo de uso & Origem \\
\hline \multicolumn{6}{|l|}{ Adoxaceae } \\
\hline $\begin{array}{l}\text { Sambucus australis } \\
\text { Cham. \& Schltdl. }\end{array}$ & Sabugueiro & $\begin{array}{l}\text { Febre, diabetes, } \\
\text { gripe sarampo }\end{array}$ & $\begin{array}{c}\text { Folha e } \\
\text { flores }\end{array}$ & Chá/Infusão & Exótica \\
\hline \multicolumn{6}{|l|}{ Amaryllidaceae } \\
\hline $\begin{array}{l}\text { Allium ascalonium Bory } \\
\text { \& Chaub. }\end{array}$ & Cebola branca & $\begin{array}{c}\text { Inflamação/ } \\
\text { banho }\end{array}$ & $\begin{array}{c}\text { Folhas e } \\
\text { fruto }\end{array}$ & Chá/Infusão & Exótica \\
\hline \multicolumn{6}{|l|}{ Anacardiaceae } \\
\hline $\begin{array}{c}\text { Myracrodruon urundeuva } \\
\text { M. Allemão }\end{array}$ & Aroeira & Inflamação & Casca & $\begin{array}{c}\text { Chá/ } \\
\text { cozimento/ } \\
\text { Banho/ } \\
\text { Garrafada }\end{array}$ & Caatinga \\
\hline \multicolumn{6}{|l|}{ Apiaceae } \\
\hline Anethum graveolens L. & Endro & $\begin{array}{l}\text { Preventivo do } \\
\text { câncer }\end{array}$ & $\begin{array}{l}\text { Frutos e } \\
\text { sementes }\end{array}$ & Chá/Infusão & Exótica \\
\hline Pimpinella anisum L. & Erva doce & Calmante & $\begin{array}{c}\text { Frutos e } \\
\text { sementes }\end{array}$ & Chá/Infusão & Exótica \\
\hline \multicolumn{6}{|l|}{ Asphodelaceae } \\
\hline Aloe vera(L.) Burm. f. & Erva babosa & Anti-inflamatório & Folhas & Macerado & Exótica \\
\hline \multicolumn{6}{|l|}{ Asteraceae } \\
\hline Matricaria chamomilla L. & Camomila & Calmante & $\begin{array}{l}\text { Folhas e } \\
\text { flores }\end{array}$ & Chá/Infusão & Exótica \\
\hline Helianthus annuus L. & Girassol & $\begin{array}{c}\text { Febre, labirintite, } \\
\text { enxaqueca }\end{array}$ & $\begin{array}{l}\text { Folhas e } \\
\text { sementes }\end{array}$ & $\begin{array}{l}\text { Chál } \\
\text { cozimento }\end{array}$ & Exótica \\
\hline \multicolumn{6}{|l|}{ Amaranthaceae } \\
\hline $\begin{array}{l}\text { Chenopodium } \\
\text { ambrosioides L. }\end{array}$ & Mastruz & $\begin{array}{c}\text { Antiparasitas } \\
\text { intestinais }\end{array}$ & $\begin{array}{c}\text { Folhas, } \\
\text { flores e } \\
\text { sementes }\end{array}$ & Macerado & Exótica \\
\hline Lamiaceae & & & & & \\
\hline
\end{tabular}




\begin{tabular}{|c|c|c|c|c|c|}
\hline Mentha $x$ villos $a$ Huds & $\begin{array}{l}\text { Hortelã } \\
\text { miúdo }\end{array}$ & $\begin{array}{l}\text { Gripe, tosse e } \\
\text { febre }\end{array}$ & Folha & Chá/Infusão & Exótica \\
\hline $\begin{array}{c}\text { Plectranthus amboinicus } \\
\text { (Lour.) Spreng. }\end{array}$ & $\begin{array}{l}\text { Hortelã } \\
\text { Grande }\end{array}$ & $\begin{array}{l}\text { Tosse, gripe, } \\
\text { secreção }\end{array}$ & Folha & Chá/Infusão & Exótica \\
\hline $\begin{array}{c}\text { Plectranthus } \\
\text { barbatus Andrews }\end{array}$ & Boldo & Dor na barriga & Folha & Chá/Infusão & Exótica \\
\hline Rosmarinus officinalis $\mathrm{L}$. & Alecrim & $\begin{array}{c}\text { Gripe, } \\
\text { tosse, febre, } \\
\text { hipertensão }\end{array}$ & $\begin{array}{l}\text { Folhas e } \\
\text { flores }\end{array}$ & Chá/Infusão & Exótica \\
\hline Ocimum basilicum L. & Manjericão & Tosse & Folha e flor & Chá/Infusão & Exótica \\
\hline \multicolumn{6}{|l|}{ Lauraceae } \\
\hline $\begin{array}{c}\text { Cinnamomum zeylanicum } \\
\text { Blume }\end{array}$ & Canela & Anti-inflamatório & $\begin{array}{c}\text { Casca e } \\
\text { folha }\end{array}$ & $\begin{array}{c}\text { Chá/ } \\
\text { cozimento }\end{array}$ & Exótica \\
\hline Laurus nobilis L. & Louro & Calmante & Folha & $\begin{array}{c}\text { Chá/ } \\
\text { cozimento }\end{array}$ & Exótica \\
\hline \multicolumn{6}{|l|}{ Malvaceae } \\
\hline Melochia tomentosa L. & Malva rosa & Febre, inflamação & Folha & $\begin{array}{c}\text { Chá/ } \\
\text { cozimento }\end{array}$ & Caatinga \\
\hline \multicolumn{6}{|l|}{ Myrtaceae } \\
\hline $\begin{array}{c}\text { Eucalyptus globulus } \\
\text { Labill. }\end{array}$ & Eucalipto & Gripe & Folhas & Chá/Infusão & Exótica \\
\hline Psidium guajava L. & Goiaba & Diarreia & Folhas & $\begin{array}{c}\text { Chá/ } \\
\text { cozimento }\end{array}$ & Exótica \\
\hline \multicolumn{6}{|l|}{ Pedaliceae } \\
\hline Sesamum indicum L. & Gergelim & $\begin{array}{l}\text { Reumatismo, } \\
\text { hipertensão, } \\
\text { anemia }\end{array}$ & Sementes & Macerado & Exótica \\
\hline \multicolumn{6}{|l|}{ Poaceae } \\
\hline $\begin{array}{c}\text { Cymbopogon citratus } \\
\text { (DC.) Stapf }\end{array}$ & Capim Santo & $\begin{array}{c}\text { Calmante, dor } \\
\text { de cabeça }\end{array}$ & Folha & Chá/Infusão & Exótica \\
\hline \multicolumn{6}{|l|}{ Rutaceae } \\
\hline $\begin{array}{l}\text { Citrus sinensis (L.) } \\
\text { Osbeck } \\
\end{array}$ & Laranja & Calmante & Folha & Chá/Infusão & Exótica \\
\hline Ruta graveolens L. & Arruda & Dor de ouvido & Folha & Macerado & Exótica \\
\hline \multicolumn{6}{|l|}{ Verbenaceae } \\
\hline $\begin{array}{c}\text { Lippia alba (Mill.) N.E. } \\
\text { Br. }\end{array}$ & Erva cidreira & Calmante & $\begin{array}{c}\text { Folhas e } \\
\text { flores }\end{array}$ & Chá/Infusão & Exótica \\
\hline \multicolumn{6}{|l|}{ Zingiberaceae } \\
\hline $\begin{array}{c}\text { Alpinia zerumbet (Pers.) } \\
\text { B.L. Burtt \& R.M. Sm. }\end{array}$ & Colônia & Febre & $\begin{array}{c}\text { Folhas e } \\
\text { rizoma }\end{array}$ & $\begin{array}{c}\text { Chá/ } \\
\text { cozimento }\end{array}$ & Exótica \\
\hline
\end{tabular}

Fonte: Elaborado pelos autores.

O número de citações individuais entre as 38 mulheres e 2 homens variou de três a cinco espécies, demonstrando que cada uma conhece o uso medicinal para $76 \%$ das 26 espécies citadas pelo grupo. Isso possivelmente se deve ao fato de estas plantas serem cultivadas e trocadas, quando necessário por vizinhos e parentes. 
Analisando as espécies citadas, verifica-se que 90\% são basicamente herbáceas cultivadas e exóticas, e duas da Caatinga (Myracrodruon urundeuva Allemão) Aroeira e (Melochia tomentosa L.) - Malva rosa. As espécies exóticas são adquiridas através de cultivos caseiros, supermercados ou doações dos vizinhos mais próximos. Comumente, essas plantas são comercializadas nas feiras livres. Contudo, no município de Gado Bravo, não há esse meio comercial, devido à ausência de raizeiros que comercializem seus produtos no mercado popular. Foram registradas em outros estudos que plantas medicinais exóticas como (Lavandula spica L. - Alfazema, Ruta graveolens L. - Arruda, Mentha x villosa Huds. - Hortelã miúda, Anethum graveolens L. - Endro) são as mais usadas pela população, devido ao vasto conhecimento tradicional e à popularização destas espécies vegetais, por serem de origem europeia, africana e asiática (BEGOSSI et al. 1993; SOUZA; FELFILI, 2006; PEREIRA et al, 2016). ao longo de cinco séculos de colonização, essas práticas são disseminadas pela cultura, através da miscigenação étnica (BENNETT; PRANCE, 2000, COSTA; MARINHO, 2016, CASTRO; FIGUEIREDO, 2019).

\subsection{Procedimentos terapêuticos}

Considerando que a terapêutica estudada põe em prática os meios adequados para aliviar ou curar os doentes, alguns procedimentos práticos foram registrados em Gado Bravo-PB. O tratamento de diferentes doenças evidencia a utilização de plantas medicinais que curam, seja em banhos de assento ou até mesmo no uso de chá via oral (Tabela 4). O modo de preparo das plantas medicinais utilizados nos procedimentos terapêuticos também apresenta o uso combinado de várias espécies vegetais, podendo inserir outros ingredientes, como álcool, mel e/ou açúcar.

Tabela 4: Formas de utilização das plantas medicinais indicadas pelos moradores do município de Gado Bravo-PB.

Forma de Preparo

\section{No de citações}

\begin{tabular}{cc}
\hline Decocção & 46 \\
\hline Infusão & 103 \\
\hline Maceração & 5 \\
\hline Suco & 5 \\
\hline Banho & 1 \\
\hline
\end{tabular}

Fonte: Elaborado pelos autores.

As plantas que são utilizadas como uso medicinal pela população local apresentam maior importância quando são referidas para problemas simples de saúde 
pública, de acordo com sistemas corporais reconhecidos pela OMS/CID-10 como: DI = Doenças Infecciosas; DP = Doenças Parasitárias; DPTS = Doenças da Pele e Tecido Subcutâneo; DS = Doenças do Sangue; TSC = Transtornos do Sistema Circulatório; TSGI = Transtornos do Sistema Gastrintestinal; TSGU = Transtornos do Sistema Gênito-Urinário; TSN = Transtornos do Sistema Nervoso; TSR = Transtornos do Sistema Respiratório; TSV = Transtornos do Sistema Visual, doenças essas que fazem parte da atenção primária à saúde.

Dessas enfermidades, as plantas mais citadas para mediar a cura ou o tratamento acometido no transtorno do sistema nervoso foram Capim Santo, Camomila, Erva Cidreira, Erva Doce. Essas espécies foram citadas por $70 \%$ dos informantes, maiores de 40 anos de idade, em decorrência de doenças acometidas por pressão alta, estresse, dores de cabeça, ansiedade, enquanto os mais jovens preferem os medicamentos alopáticos (Figura 4).

Figura 4. Citações das categorias de uso medicinal, com base nos Sistemas corporais reconhecidos pela OMS/CID-10, indicadas pelos moradores do município de Gado Bravo-PB.

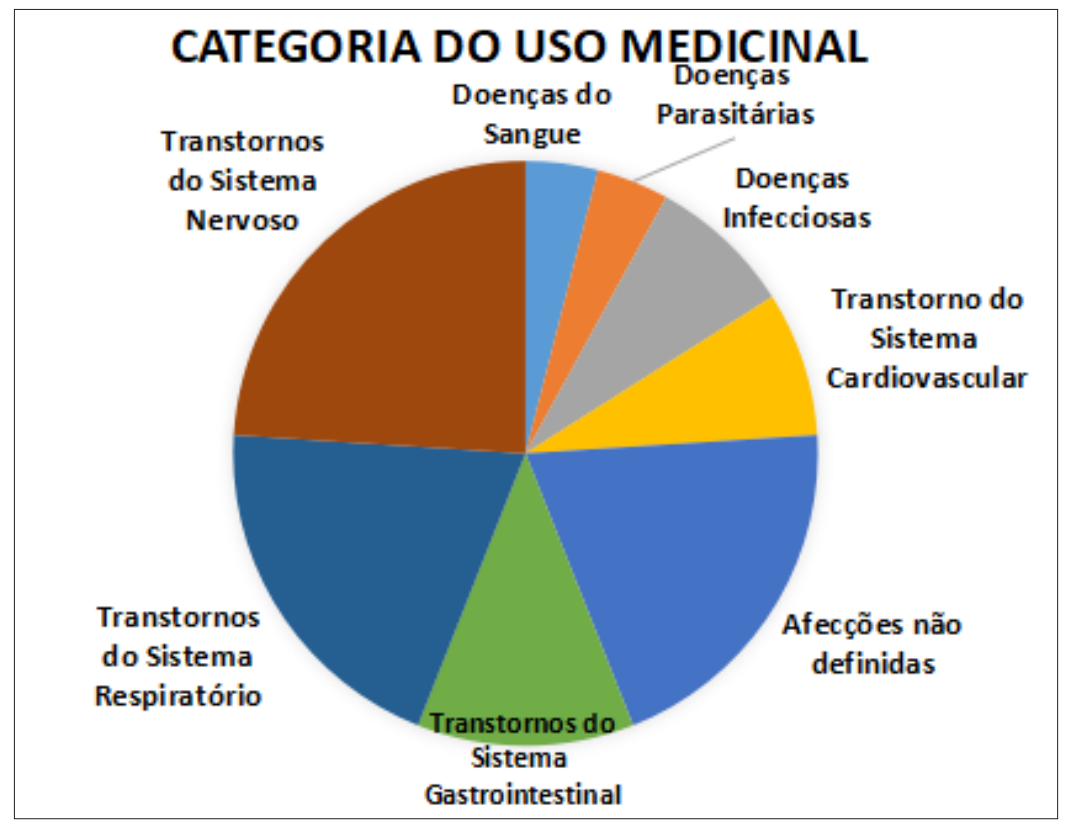

De acordo com Amorozo; Gély (1988) e Ribeiro (2019), as razões apresentadas para o uso de uma determinada planta estão de acordo com o sistema de pensamento dos informantes, com concepções de causa e efeito próprias. Embora se diferenciem de uma explicação causal científica, elas não excluem a possibilidade de uma ação 
farmacológica, devido à toxidade da planta. Um estudo mais detalhado sobre os procedimentos e administração no preparo e posologia da planta podem fornecer indícios a pesquisas farmacológicas, relacionadas aos princípios ativos. Dessa forma, seria muito útil para o sistema de saúde implantar programas de saúde da família mais eficientes.

\section{Conclusão}

O conhecimento etnobotânico dos moradores de Gado Bravo-PB remonta aos tempos do século XIX, quando a região ainda se caracterizava como rural. A prática e o uso de plantas medicinais são constantes. Apesar do tempo, constatou-se que os conhecimentos de plantas medicinais estão a ser repassados para as novas gerações através de usos, como infusão e decocção para a cura de doenças simples, do tipo transtorno do sistema respiratório, do sistema nervoso e gastrointestinal. Portanto, os moradores mais jovens preferem remédios alopáticos em vez de plantas medicinais.

Com base no que foi relatado pelos entrevistados, as partes das plantas mais utilizadas são folhas, flores e frutos. Todavia, as doenças citadas pelos moradores são de baixo risco, sendo as plantas eficazes para o tratamento e cura.

A crescente modernização e a aquisição de novos conhecimentos inibem a dinâmica cultural, os hábitos, as crenças e os valores típicos da vida urbana. O resgate ao conhecimento das memórias vivas dos antigos moradores nos leva a pensar no poder de cura que as plantas apresentavam. Porém esses valores não são reconhecidos pela sociedade contemporânea.

Neste estudo, as plantas citadas pelos entrevistados foram compradas nos supermercado e algumas encontradas nos quintais dos moradores. Entretanto este município não possui raizeiros e comerciantes na feira livre. Entre as espécies medicinais, $90 \%$ são basicamente herbáceas cultivadas e exóticas, e duas da Caatinga (Myracrodruon urundeuva Allemão) - Aroeira e (Melochia tomentosa L.) - Malva rosa. Ou seja, os moradores apresentam vínculo com o espaço, ou a vegetação Caatinga, porém não conseguem identificar as espécies medicinais, que são tradicionais deste bioma.

De acordo com o conhecimento do uso de plantas medicinais encontrado nas comunidades, as espécies foram citadas pelos entrevistados maiores de 40 anos de idade. Estes são responsáveis pelo uso cultural e permanecem mantendo vínculo com as plantas, disseminando e transmitindo saberes acerca do uso destas. 


\section{Referências}

ALBERTASSE, P.D.; THOMAZ, L.D.; ANDRADE, M.A. Plantas medicinais e seus usos na comunidade da Barra do Jucu, Vila Velha, ES. Revista Brasileira de Plantas Medicinais. v.12, n.3, p.250-260, 2010.

ALBUQUERQUE, U.P.; LUCENA, R.F.P. Métodos e técnicas de pesquisa etnobotânica. Recife: Livro Rápido/ NUPEEA, 189p. 2004.

AMOROZO, M.C.M.; GÉLY, A.L. Uso de plantas medicinais por caboclos do baixo Amazonas, Barcarena, PA, Brasil. Boletim do Museu Paraense Emílio Goeldi, Série Botânica, v.4, n.1, p.47-131, 1988.

ANDRADE, S. A. L., TRISTÃO, M. I. S.; MIGUEL, M. D.; DIAS, J. F. G.; GOMES, E. C.; BURCI, L. M.; PAULA, C. S. Fitoterápicos da relação nacional de medicamentos essenciais no Brasil. Revista Cubana de Plantas Medicinales v. 22, n. 1, 2017.

BAILEY, K. Methods of social research. 4.ed. New York:The Free Press, 588p. 1994.

BEGOSSI, A. LOPES, P.F, OLIVEIRA, L.E. C, NAKANO, H. Ecologia de pescadores artesanais da Baía de Ilha Grande. IBIO/Ministério da Justiça. Rio de Janeiro, 123 p. 2009.

BENNETT, B. C.; PRANCE, G. T. Introduced plants in the indigenous phamarcopoeia of Northern South America. Springe. Economic Botany, v. 54, n. 1, p. 90-102. 2000.

CASTRO, A. A. J. F. Florística e fitossociologia de um cerrado marginal brasileiro, Parque Estadual de Vassununga, Santa Rita do Passa Quatro- SP. Dissertação (Mestrado- Área de Concentração em Ciências Biológicas), Departamento de Biologia, Universidade Estadual de Campinas, Campinas. 240p, 1987.

CASTRO, M. R. DE. FIGUEIREDO, F. F. Saberes tradicionais, biodiversidade, práticas integrativas e complementares: o uso de plantas medicinais no Sus. Hygeia 15 (31): 56 $-70,2019$.

CERQUEIRA, T. M. G. et al. The Use of Medicinal Plants in Maceió, Northeastern Brazil: An Ethnobotanical Survey. Medicines, v. 7, n. 2, p. 7, 2020.COSTA, J.C.; MARINHO, M.G.V. Etnobotânica de plantas medicinais em duas comunidades do município de Picuí, Paraíba, Brasil. Revista Brasileira Plantas Medicinais. v.18, n.1, p.125-134, 2016.

FIEBIG, G. DE Á. PASA, M. C. As plantas medicinais na comunidade Passagem da Conceição, Mato Grosso, Brasil. Advances in Forestry Science, Cuiabá, v.5, n.1, p.237$248,2018$.

FLORENTINO, A.T.N.; ARAÚJO, E. L.; ALBUQUERQUE, U.P. Contribuições de quintais agroflorestais na conservação de plantas da Caatinga, município de Caruaru, PE, Brasil. Acta Botânica Brasílica, v.21, n.1, p.37-47, 2007. 
FREITAS, J. C.; FERNANDES, M. E. B. Uso de plantas medicinais pela comunidade de Enfarrusca, Bragança, Pará. Ciências Naturais, Belém, v. 1, n. 3, p. 11-26, set-dez. 2017.

INSTITUTO BRASILEIRO DE GEOGRAFIA E ESTATISTICA - IBGE. Cidades. Brasília, 2010. <Disponível em: http://www.cidades.ibge.gov.br/xtras/perfil >Acesso em: 12 de set. de 2017.

MACÊDO, D. G; RIBEIRO, D. A; COUTINHO, H. D. M; MENEZES, I. RA; SOUZA, M. M. A. Práticas terapêuticas tradicionais: uso e conhecimento de plantas do cerrado no estado de Pernambuco (Nordeste do Brasil). Boletim Latino-americano do Caribe de Plantas Medicinais e Aromáticas. v. 14, n. 6 p. 491-508, 2015.

MARTElli, A. CARVAlHO, L. A. H. B. de. Percepção dos moradores do distrito de Eleutério, município de Itapira-SP, acerca da utilização de plantas medicinais. Arch Health Invest, 8(2):79-84, 2019.

MARTINS, A. G.; ROSÁRIO, D. L.; BARROS, M. N.; JARDIM, M. A. G. Levantamento etnobotânico de plantas medicinais, alimentares e tóxicas da Ilha do Combu, Município de Belém, Estado do Pará, Brasil. Revista Brasileira de Farmácia. v. 86, n. 1, p. 21-30, 2005.

MARTINS, F. R. O método de quadrantes e a fitossociologia de uma floresta residual no interior do Estado de São Paulo: Parque Estadual de Vassununga.. Tese (DoutoradoÁrea de Concentração em Ciências), Departamento de Biociências, Universidade de São Paulo, São Paulo. p. 239, 1979.

NÓBREGA, J. S.; SILVA F. de A.; BARROSO, R. F.; CRISPIM, D. L.; OLIVEIRA, C. J. A. Avaliação do conhecimento etnobotânico e popular sobre o uso de plantas medicinais junto a alunos de graduação. Revista Brasileira de Gestão Ambiental. v. 11, n.1, p.07 $13,2017$.

OliveIRA, G. L., OLIVEIRA, A. F. M.; ANDRADE, L. H. C. Plantas medicinais utilizadas na comunidade urbana de Muribeca, Nordeste do Brasil. Acta Botânica brasílica. v. 24, n. 2, p. 571-577, 2010.

OLIVEIRA, V. B. DE; MEZZOMO, T. R. MORAES, E. F. DE. Conhecimento e Uso de Plantas Medicinais por Usuários de Unidades Básicas de Saúde na Região de Colombo, PR. Revista Brasileira de Ciências da Saúde. Volume 22 Número 1. Páginas 57-64, 2018.

OMS - Organização Mundial de Saúde. Traditional medicine: definitions. Disponível em: http://www.who.int/medicines/areas/ traditional/definitions/en/>. Acesso em: 10 set. 2017.

PEREIRA, T. M. S.; MOURA, D. C.; RODRIGUES, E. M. Análise fitogeográfica das plantas medicinais comercializadas nas feiras livres de Campina Grande-PB, Brasil Conidis, 2016. 
PERNA, T. A.; FERREIRA, A. P. N. L. A Revisão Bibliométrica Sobre o Cultivo de Plantas Medicinais em Quintais Urbanos em Diferentes Regiões do Brasil (2009-2012). UNOPAR Científicos Ciências Biológicas Saúde. v. 16, n. 1, p. 61-7; 2014.

PIO, I. D. S. L. et al. Traditional knowledge and uses of medicinal plants by the inhabitants of the islands of the são francisco river, Brazil and preliminary analysis of rhaphiodon echinus (Lamiaceae). Brazilian Journal of Biology, v. 79, n. 1, p. 87-99, 2019.

RIBEIRO, L. H. L. Análise dos programas de plantas medicinais e fitoterápicos no Sistema Único de Saúde (SUS) sob a perspectiva territorial. Ciência \& Saúde Coletiva, 24(5):1733-1742, 2019.

RODRIGUES, W. Competitividade e mudança institucional na cadeia produtiva de plantas medicinais no Brasil. Interações, v. 17, n. 2, p. 267 - 277, 2016.

SILVA, C. G.; MARINHO, M. G. V.; LUCENA, M. F. A.; COSTA, J. G. M. Levantamento etnobotânico de plantas medicinais em área de Caatinga na comunidade do Sítio Nazaré, município de Milagres, Ceará, Brasil. Revista Brasileira de Plantas Medicinais. v. 17, n. 1, p.133-142, 2015.

SOUZA, C.D.; FELFILI, J.M. Uso de plantas medicinais na região de Alto Paraíso de Goiás, GO, Brasil. Acta Botânica Brasílica, v. 20, n. 1, p.135-142, 2006. 
